\title{
Effect of Microsphaeropsis sp. Strain P130A on Germination and Production of Sclerotia of Rhizoctonia solani and Interaction Between the Antagonist and the Pathogen
}

\author{
Odile Carisse, Souad El Bassam, and Nicole Benhamou
}

First and second authors: Agriculture and Agri-Food Canada, Horticultural Research and Development Centre, 430 Gouin Blvd., St Jean-surRichelieu, Québec, Canada, J3B 3E6; and third author: Recherches en sciences de la vie et de la santé, Faculté des sciences de l'agriculture et de l'alimentation, Université Laval, Sainte-Foy, Québec, Canada, G1K 7P4. Accepted for publication 10 May 2001.

\begin{abstract}
Carisse, O., El Bassam, S., and Benhamou, N. 2001. Effect of Microsphaeropsis sp. strain $\mathrm{P} 130 \mathrm{~A}$ on germination and production of sclerotia of Rhizoctonia solani and interaction between the antagonist and the pathogen. Phytopathology 91:782-791.

Microsphaeropsis sp. strain P130A was evaluated for the control of tuber-borne inoculum of Rhizoctonia solani based on the viability of sclerotia produced in vitro and on both the viability and production of tuber-borne sclerotia. The interactions between the antagonist and the pathogen, as well as the effect of the toxins produced by the antagonist on mycelial growth of $R$. solani were studied using transmission electron microscopy. On sclerotia produced in vitro, for all incubation periods (1 to 42 days), Microsphaeropsis sp. significantly reduced germination. Percent germination of sclerotia treated with Microsphaeropsis sp. decreased with increasing incubation period from an average of $82.0 \%$ after 1 day to stabilize at an average of 5.8\% after 35 days. Similarly, percent germination of tuber-borne sclerotia was significantly lower when tubers were treated with Microsphaeropsis sp. Both $2 \%$ formaldehyde and $\mathrm{Mi}$ -

to approximately $10 \%$ after 42 days of incubation at $4{ }^{\circ} \mathrm{C}$. Furthermore, on tubers treated with the antagonist, the number of sclerotia per square centimeter decreased from 1.6 to 0.5 during the 8 months of storage at $4^{\circ} \mathrm{C}$, whereas an increase from 1.2 to 7.8 sclerotia per square centimeter was observed on untreated tubers. Microsphaeropsis sp. (strain P130A) colonized hyphae of $R$. solani within 4 days after contact on culture media. Transmission electron microscopic observations showed that the antagonist induced a rupture of the pathogen plasma membrane and that a chitin-enriched matrix was deposited at sites of potential antagonist penetration. Host penetration was not associated with pathogen cell wall alterations, which occurred at the time of progress of the antagonist in the pathogen cytoplasm. In the presence of a crude extract of Microsphaeropsis sp., cells of $R$. solani showed cytoplasm disorganization and breakdown of plasma membranes. Antibiosis and mycoparasitism were involved in the antagonism of $R$. solani by Microsphaeropsis sp., but the sequence by which these events occur, as well as the significance of wall appositions produced by $R$. solani, is yet to be established.
\end{abstract} crosphaeropsis $\mathrm{sp}$. treatments significantly reduced sclerotia germination
Additional keywords: damping-off, potato diseases, stem canker, storage rot.
Rhizoctonia solani Kühn is an ubiquitous, soilborne pathogen known for causing stem canker, storage rot, aerial blight, and seedling damping-off diseases in many crops including canola, carrot, soybean, and potato $(23,32,36)$. The wide host range of this pathogen, as well as its ability to survive as sclerotia under adverse soil environmental conditions, have markedly reduced the potential of crop rotation as a management strategy. In practice, control of Rhizoctonia-incited diseases relies mainly on fungicides, used alone or in combination with other chemicals (22). However, the current success of fungicides in controlling Rhizoctonia diseases is greatly compromised by a number of limitations that include chemical-mediated induced resistance of $R$. solani strains and increasing concerns about the harmful impact of repeated fungicide applications (26).

Over the last decades, efforts have been directed toward developing new alternatives to chemical disease control (15). In addition to the use of binucleate isolates of $R$. solani (20), biocontrol agents such as endophytic bacteria (34) and fungal antagonists including Trichoderma spp. $(18,24)$, Verticillium biguttatum (28), and Gliocladium virens $(21,27)$ have shown potential for practical applications in agriculture. In spite of such an interest in introducing alternatives to chemical pesticides, very few bio-

Corresponding author: O. Carisse; E-mail address: carisseo@em.agr.ca

Publication no. P-2001-0612-01R

(C) 2001 The American Phytopathological Society control agents are, so far, available for commercial use. The trend toward introducing new management approaches depends on an array of criteria, one of them being a deep knowledge of the mode of action of the selected biocontrol agents. Because of the close link between antagonist function and performance, the first step toward understanding the mechanisms underlying the antagonistic activity of a selected agent is to investigate, under defined environmental conditions, its ability to produce antibiotics, to parasitize its hosts, and to compete for nutrients or space (29). Recent studies have provided some evidence that biocontrol activity is more than a simple process involving a single metabolite but rather involves a series of complex events expressed in a controlled sequence $(1,4,5)$. Therefore, elucidating the sequence of events leading to successful biological control of pathogens is a prerequisite for subsequent in vivo bioassay tests to confirm activity under more realistic conditions.

Potato is the fourth most important food crop in the world. As with many other agricultural crops, potatoes are subjected to fungal diseases, including black scurf caused by $R$. solani. Black scurf reduces tuber quality and therefore marketability. Although the disease engenders economic losses during most years, it rarely affects all potato fields. A rotation of at least 3 to 5 years is often necessary to significantly reduce losses caused by $R$. solani. Consequently, avoiding inoculum introduction via contaminated tubers is a key factor in black scurf management. A study by Chand and Logan (13) on the dynamics of sclerotia production in relation to tuber maturity showed that few sclerotia are produced before plant 
senescence. Sclerotia production increases with increasing decay of roots and stolons and continues during storage (13). In that context, our long-term objective was to investigate the potential of a biocontrol agent to both prevent production of sclerotia on tubers and reduce the viability of those produced during storage. This approach should be useful for the fields free of $R$. solani soil inoculum and to avoid field contamination, in addition to offering the advantages of not relying on a soil biocontrol agent and requiring a smaller quantity of biofungicide.

Microsphaeropsis sp. strain P130A, a coelomycete isolated from dead apple leaves, is an antagonist that is gaining interest as a powerful biocontrol agent, because it has recently been found to exert strong antimicrobial activity against Venturia inaequalis, the apple scab pathogen $(8,12,31)$. Recent studies have shown that Microsphaeropsis sp. strain P130A is capable of inhibiting in vitro and field-produced ascospores of Venturia inaequalis and in vitroproduced ascospores of Gibberella zeae $(11,12,31)$. Because both Venturia inaequalis and Gibberella zeae produce ascospores in melanized structures (pseudothecia and perithecia), it is hypothesized that Microsphaeropsis sp. (isolate P130A) could inhibit the production and germination of other melanized fungal structures such as sclerotia.

The main objective of this study was to evaluate the potential of Microsphaeropsis sp. strain P130A to biologically control $R$. solani by reducing the viability and production of tuber-borne sclerotia. More specifically, the objectives were to (i) evaluate the effect of the antagonist on the viability of in vitro-produced sclerotia; (ii) evaluate the effect of Microsphaeropsis sp. on the viability and production of tuber-borne sclerotia; (iii) investigate, by transmission electron microscopy (TEM), the interaction between Microsphaeropsis sp. and R. solani; and (iv) investigate ultrastructurally the effect of the toxins produced by Microsphaeropsis sp. on the hyphae of $R$. solani.

\section{MATERIALS AND METHODS}

Fungal isolates and growth conditions. Microsphaeropsis sp. strain P130A was isolated from dead apple leaves in a Quebec orchard (10) and has previously been reported as an effective mycoparasite of Venturia inaequalis $(8,12)$. It was maintained on potato dextrose agar (PDA; Difco Laboratories, Detroit) medium at room temperature $\left(22\right.$ to $25^{\circ} \mathrm{C}$ ). The isolate of $R$. solani AG-3 isolated from sclerotia collected from potato tubers was supplied by $\mathrm{T}$. Paulitz (MacDonald College of McGill University, Ste Anne-deBellevue, Quebec, Canada) and was cultured on PDA at room temperature. For the antibiotic assays, $R$. solani was grown in potato dextrose broth (PDB; Difco) medium for 1 week on a rotary shaker (150 rpm) at room temperature.

Effect of Microsphaeropsis sp. on the viability of in vitroproduced $R$. solani sclerotia. $R$. solani was grown on PDA at room temperature for 5 to 8 weeks. Sclerotia were removed from the surface of the culture with a sterile scalpel and kept in sterile glass vials until used for the experiment (maximum of 1 week). Sclerotia of approximately the same size (3 to $4 \mathrm{~mm}$ in diameter) were placed at the periphery of a 15-day-old culture of Microsphaeropsis sp. (eight sclerotia per plate) and incubated at room temperature for up to 42 days. Similarly, sclerotia were placed on a moist filter paper in a petri dish and treated with Microsphaeropsis $\mathrm{sp}$. applied at a rate of $50 \mu \mathrm{l}$ per sclerotia of a spore suspension of $5.5 \times 10^{8}$ spores per $\mathrm{ml}$ per sclerotia (percent germination of 90 to $94 \%$ ). The spore suspension was made from frozen spores $\left(-80^{\circ} \mathrm{C}\right)$ of Microsphaeropsis sp. strain $\mathrm{P} 130 \mathrm{~A}$ provided by Philom Bios, Saskatoon, Canada. For both tests, viability of sclerotia was evaluated after $1,3,7,14,21,28,35$, and 42 days by harvesting one sclerotium from each plate and placing it on the surface of water agar plates for $24 \mathrm{~h}$ at room temperature. Viability was evaluated based on hyphal growth observed at $\times 40$ under a dissecting microscope. Sclerotia were considered viable when typical Rhizoctonia-like hyphae grew from the sclerotia. Viability was recorded as the incidence of viable sclerotia expressed as a percentage. A completely randomized design was used with 30 plates per treatment, and water-treated sclerotia served as a control. The entire experiment was conducted twice.

Effect of Microsphaeropsis sp. on the viability and production of tuber-borne $\boldsymbol{R}$. solani sclerotia. During the summer of 1999 (end of May to end of August), infected tubers were produced by planting seed tubers (cv. Kennebec) in seedbeds that had been previously covered with barley grains infested with $R$. solani at a rate of $100 \mathrm{~g}$ of grain per meter of row. Potatoes were grown according to standard recommendations. A foliar fungicide (Bravo) was applied twice to control late blight (Phytophthora infestans [Mont.] de Bary). In August, tubers were harvested and stored at $4{ }^{\circ} \mathrm{C}$ until needed for the experiments. Prior to treatment, tubers were dipped in tap water to remove excess soil and air-dried. Infected tubers were dipped for $20 \mathrm{~min}$ in 4 liters of either water, $2 \%$ formaldehyde, or a suspension of $5.5 \times 10^{8}$ spores per $\mathrm{ml}$ of Microsphaeropsis sp. made from frozen spores as described previously. The tubers were drained, placed in plastic trays (five tubers per tray) enclosed in black plastic bags to ensure high relative humidity, and incubated at $4^{\circ} \mathrm{C}$.

To evaluate sclerotial viability, sclerotia that were 3 to $4 \mathrm{~mm}$ in size were removed from the treated tubers after 14, 21, 28, 35, 42, and 56 days and placed on the surface of water agar plates for $24 \mathrm{~h}$ at room temperature. Viability was evaluated based on hyphal growth observed at $\times 40$ under a dissecting microscope as described previously. The experimental design was completely randomized, each treatment having five trays of five tubers from each of which five sclerotia were evaluated (total of 125 sclerotia). Water-treated tubers served as control, and the test was conducted twice.

To evaluate the effects of treatments on the production of sclerotia during storage, the number of sclerotia per square centimeter of tubers was counted before storage and once a month over a period of 8 months, from September to April. The number of sclerotia was counted at $\times 40$ under a dissecting microscope on 10 circles of $1 \mathrm{~cm}^{2}$ selected at random at the beginning of the experiment. The experiment had a completely randomized design, each treatment having six trays of five tubers (total of 30 tubers). Water-treated tubers served as controls, and the tests were conducted twice.

Data analysis. Homogeneity of variance ( $F$ test) was used to determine whether the data from two experimental runs could be pooled. Analysis of variance (ANOVA) was used to test the significance of Microsphaeropsis sp. or 2\% formaldehyde treatment on sclerotia viability or production, expressed as a percentage of germinated sclerotia and number of sclerotia per square centimeter, respectively. Multiple comparison tests (LSD) were used to detect significant differences among means, and orthogonal comparisons were used to compare the treatments with the control (water-treated sclerotia) at the 0.05 confidence level (37). Repeated measures analyses were conducted to test the effect of incubation time on sclerotia viability or production (Manova procedure). Statistical analyses were conducted using the SAS software program (SAS Institute Inc., Cary, NC).

Dual culture tests. Hyphal interactions between Microsphaeropsis $\mathrm{sp}$. and $R$. solani were studied according to the following procedure. A mycelial disk ( $5 \mathrm{~mm}$ in diameter), cut from the edge of an actively growing colony of Microsphaeropsis sp., was placed on the surface of a freshly prepared PDA medium. Ten days later, a mycelial disk of $R$. solani ( $5 \mathrm{~mm}$ in diameter) was placed $3 \mathrm{~cm}$ from the emerging colony of Microsphaeropsis sp. The experiment was repeated five times. Petri dishes were incubated at $25^{\circ} \mathrm{C}$ under continuous light. Mycelial samples from the interaction region between both fungi were collected 4 days after the first apparent contact and processed for electron microscopy. An average of five samples from five different petri dishes was collected. 
Sample processing for histological and ultrastructural observations. Mycelial samples from the interaction region, as well as samples from pure cultures of each fungus, were fixed with $2 \%$ ( $\mathrm{vol} / \mathrm{vol}$ ) glutaraldehyde in $0.1 \mathrm{M}$ sodium cacodylate buffer $(\mathrm{pH} 7.2)$ for $2 \mathrm{~h}$ at room temperature and overnight at $4^{\circ} \mathrm{C}$. They were postfixed with $1 \%$ (wt/vol) osmium tetroxide in the same buffer for $1 \mathrm{~h}$ at $4^{\circ} \mathrm{C}$. Samples were, thereafter, dehydrated in a graded ethanol series and embedded in Epon 812 (JBEM Chemical Co., PointeClaire, Quebec, Canada). Ultrathin sections $(0.1 \mu \mathrm{m})$ were collected on Formvar-coated nickel grids (JBEM Chemical) and were either contrasted with uranyl acetate and lead citrate for direct examination with an electron microscope (JEOL $1200 \mathrm{EX}$; JEOL, Tokyo, Japan) operating at $80 \mathrm{kV}$, or processed for cytochemical labeling. An average of 10 sections per sample was examined.

Cytochemical labeling. Colloidal gold (BDH Chemicals, Montreal, Quebec, Canada), with an average particle diameter of $12 \mathrm{~nm}$, was prepared according to Frens (19). For studying the distribution of chitin, a linear polysaccharide of $\beta$-1, 4-linked $N$ acetylglucosamine residues, wheat germ agglutinin (WGA), a lectin with $\mathrm{N}$-acetylglucosamine-binding specificity (2) (Sigma Chemical, St. Louis), was used in a two-step procedure. Ovomucoid, a high molecular weight glycoprotein (Sigma Chemical), was chosen as a second step reagent because of its specific binding affinity for WGA (2). This glycoprotein was complexed to colloidal gold at $\mathrm{pH}$ 5.4. Sections were incubated on a drop of phosphate-buffered saline (PBS) at $\mathrm{pH} 7.2$ for $5 \mathrm{~min}$ and transferred on a drop of WGA $(25 \mu \mathrm{g} / \mathrm{ml}$ in PBS, $\mathrm{pH}$ 7.2) for 30 to $60 \mathrm{~min}$ at room temperature in a moist chamber. After thorough washing with PBS (pH 7.2), sections were incubated on the ovomucoid-gold complex (1:30 in PBS/polyethylene glycol). Sections were washed with PBS, rinsed with distilled water, and contrasted with uranyl acetate and lead citrate.

Specificity of the labeling obtained was assessed through various control tests including (i) incubation with WGA to which was previously added $N, N^{\prime}, N^{\prime \prime}$-triacetylchitotriose $(1 \mathrm{mg} / \mathrm{ml}$ in $\mathrm{PBS})$; (ii) incubation with WGA, followed by uncomplexed ovomucoid, and finally by ovomucoid-gold complex; and (iii) direct incubation with the gold-complexed ovomucoid with the lectin step omitted.

Effect of active metabolites from Microsphaeropsis sp. on $\boldsymbol{R}$. solani growth and development. Liquid cultures, initiated by inoculating PDB with mycelial disks, taken from the margin of actively growing Microsphaeropsis colonies, were submitted to double filtration through Whatman No. 1 filter paper. The recovered filtrate was extracted repeatedly with chloroform $\left(\mathrm{CHCl}_{3}\right)$. The inhibitory effect of the crude extract, obtained from Microsphaeropsis sp. cultures, on growth and development of $R$. solani was evaluated by plate assays. The extract, both crude or diluted 1:2 and 1:4 in chloroform, was deposited in wells cut in the agar

TABLE 1. Effect of Microsphaeropsis sp. on the viability of Rhizoctonia solani sclerotia produced in vitro

\begin{tabular}{lcccc}
\hline \multirow{2}{*}{$\begin{array}{l}\text { Incubation } \\
\text { period (days) }\end{array}$} & \multicolumn{4}{c}{ Percent viability } \\
\cline { 2 - 5 } & Control $^{\mathrm{y}}$ & Mycelium & Control & Spores \\
\hline 1 & $95.4 \mathrm{ab}$ & $83.8 \mathrm{a}$ & $94.0 \mathrm{~cd}$ & $80.7 \mathrm{a}$ \\
3 & $95.4 \mathrm{ab}$ & $65.6 \mathrm{~b}$ & $94.7 \mathrm{~b}-\mathrm{d}$ & $60.7 \mathrm{~b}$ \\
7 & $95.1 \mathrm{ab}$ & $29.2 \mathrm{c}$ & $94.7 \mathrm{~b}-\mathrm{d}$ & $29.4 \mathrm{c}$ \\
14 & $96.2 \mathrm{a}$ & $22.3 \mathrm{~d}$ & $93.1 \mathrm{~d}$ & $21.6 \mathrm{~d}$ \\
21 & $97.1 \mathrm{a}$ & $12.3 \mathrm{e}$ & $95.8 \mathrm{bc}$ & $11.0 \mathrm{e}$ \\
28 & $93.3 \mathrm{bc}$ & $8.0 \mathrm{f}$ & $98.4 \mathrm{a}$ & $7.8 \mathrm{f}$ \\
35 & $90.6 \mathrm{c}$ & $5.1 \mathrm{~g}$ & $96.1 \mathrm{~b}$ & $6.2 \mathrm{~g}$ \\
42 & $91.8 \mathrm{c}$ & $6.1 \mathrm{~g}$ & $96.2 \mathrm{~b}$ & $6.0 \mathrm{~g}$ \\
LSD & 2.7 & 1.3 & 2.1 & 1.2 \\
\hline
\end{tabular}

y Values within columns followed by the same letter are not significantly different according to the LSD test $(P<0.05)$.

${ }^{\mathrm{z}}$ Control, water-treated sclerotia. medium. One day later, 5-mm disks of $R$. solani were placed at $3 \mathrm{~cm}$ from the wells. Control tests included wells filled with either water or chloroform. Three replicates were carried out for each dilution, as well as for the controls. Mycelial samples were collected in areas adjacent to the wells and processed for electron microscopy as described previously.

\section{RESULTS}

Effect of Microsphaeropsis sp. on the viability of in vitroproduced $\boldsymbol{R}$. solani sclerotia. The data from the two experimental runs of each test (antagonist culture and filter paper) were pooled based on homogeneity of variance $(P>0.05)$. For both tests, percent germination of water-treated sclerotia remained high, between 90.6 to $98.4 \%$. The percent germination of watertreated sclerotia remained high for all incubation periods, although significant differences in percent germination over time were detected (Table 1). For both tests and for all incubation periods, percent germination of sclerotia treated with Microsphaeropsis sp. was significantly lower $(P<0.0001)$ than for the water-treated sclerotia (Table 1). Percent germination of treated sclerotia decreased with increasing incubation period, from an average of $82.0 \%$ after 1 day to stabilize after 35 days at an average of $5.8 \%$ (Table 1).

Effect of Microsphaeropsis sp. on the viability and production of tuber-borne $\boldsymbol{R}$. solani sclerotia. Based on homogeneity of variance, the data from the two experimental runs were pooled $(P>0.05)$. Percent germination on the water-treated sclerotia varied from 76.5 to $83.3 \%$. Overall, percent germination did not vary significantly over time, except for 14 days of incubation in which percent germination was significantly lower than for the other incubation periods (Table 2). Percent germination of sclerotia treated with $2 \%$ formaldehyde decreased from 82.3 to $10.7 \%$ with increasing incubation period (Table 2). When sclerotia were treated with Microsphaeropsis sp., percent sclerotia germination was reduced to $30.7 \%$ after 14 days of incubation, which further reduced to 8.8 to $11.7 \%$ for the other incubation periods. Repeated measures analysis revealed that there was a significant effect of incubation period on percent germination for the sclerotia treated with formaldehyde, Microsphaeropsis sp., or water $(P<0.0001)$, and that the effect of the treatment varied over time $(P<0.005)$ (Table 2). Both ANOVA and orthogonal contrast indicated that for all incubation periods, the application of Microsphaeropsis sp. on sclerotia significantly $(P<0.0001)$ reduced sclerotia germination compared with the control. Similarly, percent germination was significantly lower on sclerotia treated with Microsphaeropsis sp. than with the formaldehyde treatment when incubation periods were shorter than 35 days, however, there were no significant differences after 42 and 56 days of incubation (Table 2).

On tubers treated with water and with $2 \%$ formaldehyde, the number of sclerotia per square centimeter increased over 8 months of storage from an average of 1.2 to 7.8 and 1.2 to 3.6, respectively (Fig. 1). However, the number of sclerotia on formaldehyde-treated tubers was significantly lower $(P<0.05)$ than on water-treated tubers (Fig. 1). In contrast, on tubers treated with Microsphaeropsis sp., the number of sclerotia per square centimeter decreased with increasing storage time from an average of 1.6 to 0.5 (Fig. 1). The effects of tuber treatment became significant only after 4 months of storage, and the differences in the number of sclerotia per square centimeter between treatments increased with increasing storage time. Both ANOVA and orthogonal contrast indicated that for storage time greater than 2 months, the application of Microsphaeropsis sp. on infected tubers significantly $(P<0.0001)$ reduced the lower numbers of sclerotia per square centimeter compared with the control. Repeated measure analysis revealed that storage time had a significant effect $(P<$ $0.0001)$ on the number of sclerotia per square centimeter on the tubers treated with formaldehyde, Microsphaeropsis sp., or water 
(untreated) and that the effect of tuber treatment on sclerotia production varied over time $(P<0.005)$.

Fungal growth in dual cultures. In petri dish dual cultures, the first apparent contact between hyphae of both fungi occurred within 2 days of inoculation. At that time, light microscope examinations of the interaction region showed that Microsphaeropsis sp. hyphae had become intertwined with those of $R$. solani. In the following days, Microsphaeropsis sp. mycelium grew abundantly on Rhizoctonia hyphae and colonized the agar medium. By the fourth day after inoculation, the invasive growth of the antagonist progressed and a massive secretion of brown pigments was observed.

TEM observations: Investigations of the cytological events between Microsphaeropsis sp. and $\boldsymbol{R}$. solani. When grown in single cultures, $R$. solani hyphae showed an ultrastructure similar to that previously described (4). Cells were delimited by a thick cell wall and contained a dense polyribosome-enriched cytoplasm in which a large number of organelles including mitochondria, endoplasmic reticulum, nuclei, and lipid bodies were found (Fig. 2A). Upon incubation of sections from these individual colonies of $R$. solani with the WGA-ovomucoid-gold complex for localizing $\mathrm{N}$-acetylglucosamine residues (chitin), an intense labeling was specifically associated with the cell walls and the septa (Fig. 2B). Investigations of mycelial samples collected from the interaction region 4 days after inoculation showed that Microsphaeropsis hyphae established close contact with the host cells, causing some apparent mechanical pressure (Fig. 2C). At that time after inoculation, $R$. solani cells were surrounded by numerous hyphae of Microsphaeropsis sp., which were easily recognized by their smaller diameter and by the strong electron density of their protoplasm (Fig. 2C). Most cells of the pathogen (nearly 90\%) appeared highly damaged, judged by the retraction or the rupture of the plasma membrane and by the pronounced disorganization of the cytoplasm (Fig. 2C). Organelles also suffered serious damage, evidenced by the frequent disruption of vesicles (Fig. 2C, arrows) and by the alteration of mitochondria and lipid bodies, which in some cases were no longer visible.

Observations at a higher magnification revealed that contact between the two fungi was frequently mediated by an amorphous matrix that was intensely labeled with the WGA-ovomucoid-gold complex (Fig. 2D). This chitin-enriched matrix appeared to originate from the antagonist cell wall and to stick to the pathogen cell surface. Interestingly, attachment of the antagonist to its host coincided with an apparent thickening of the pathogen cell wall at the sites of potential penetration (Fig. 2D, arrow). Subsequent splitting of the thickened wall layers was accompanied by the deposition of an amorphous matrix that increased in size (Fig. 2E) to finally form stratified, hemispherical deposits (Fig. 2F). Such newly formed wall appositions were heavily labeled by the WGA-ovomucoid-gold complex (Fig. 2F).

Penetration of the antagonist occurred through localized ruptures of the pathogen cell wall (Fig. 3A and B, arrow). Channels of penetration were often much narrower than the average hyphal diameter and were usually associated with little wall displacement

TABLE 2. Effect of Microsphaeropsis sp. strain P130A on the viability of tuber-borne Rhizoctonia solani sclerotia

\begin{tabular}{lccc}
\hline \multirow{2}{*}{$\begin{array}{l}\text { Incubation } \\
\text { period (days) }\end{array}$} & \multicolumn{3}{c}{ Treatment $^{\mathrm{z}}$} \\
\cline { 2 - 4 } & Control & 2\% formaldehyde & Microsphaeropsis sp. \\
\hline 14 & $76.5 \mathrm{~b}$ & $81.2 \mathrm{a}$ & $30.7 \mathrm{c}$ \\
21 & $83.3 \mathrm{a}$ & $82.3 \mathrm{a}$ & $11.7 \mathrm{~b}$ \\
28 & $82.2 \mathrm{a}$ & $57.8 \mathrm{~b}$ & $8.8 \mathrm{c}$ \\
35 & $80.8 \mathrm{a}$ & $29.8 \mathrm{~b}$ & $9.3 \mathrm{c}$ \\
42 & $82.1 \mathrm{a}$ & $10.8 \mathrm{~b}$ & $9.8 \mathrm{~b}$ \\
56 & $81.1 \mathrm{a}$ & $10.7 \mathrm{~b}$ & $9.7 \mathrm{~b}$ \\
LSD & 1.7 & 2.2 & 0.8 \\
\hline
\end{tabular}

${ }^{\mathrm{z}}$ Control, water-treated sclerotia. Values within columns followed by the same letter are not significantly different according to the LSD test $(P<0.05)$.
(Fig. 3A, arrow). Attempts by the antagonist to penetrate the thickened pathogen cell wall or even the newly formed wall appositions frequently succeeded (Fig. 3C).

Host penetration did not usually coincide with marked cell wall alterations, judged by the adjacent wall portions, which remained electron dense and evenly labeled with the WGA-ovomucoid-gold complex (Fig. 3D). Only discrete features of wall alteration, characterized by the occurrence of small electron light, unlabeled areas, were observed at some distance from the channel of penetration (Fig. 3D, arrow). Host colonization frequently resulted in a strong mechanical pressure against the host hyphal cell walls, ultimately leading to an apparent burst of the host hyphae and to the release of the actively growing Microsphaeropsis hyphae (Fig. $3 \mathrm{E}$, arrow). Further ingress of the antagonist in the pathogen protoplasm coincided with extensive cell alterations, such as dissolution of the host cytoplasm, which was most often, reduced to undefined fibrillar structures (Figs. 3E and 4).

Effect of active metabolites from Microsphaeropsis sp. on $\boldsymbol{R}$. solani growth and development. Exposition of $R$. solani mycelium to chloroform alone did not apparently affect the cell integrity, evidenced by the occurrence of regularly shaped hyphae in which the plasma membrane was appressed against the cell wall and the cytoplasm filled with organelles such as mitochondria (Fig. 5A). Ultrastructural examination of $R$. solani mycelial samples, collected at the margin of wells filled with the extract from Microsphaeropsis sp. cultures, revealed that the pathogen suffered from serious damage including plasmalemma retraction and cytoplasm disorganization (Fig. 5B and E). Rhizoctonia hyphae, exposed either to the undiluted or to the 1:2 diluted Microsphaeropsis sp. extract, exhibited marked morphological alterations mainly characterized by a circonvolution of the cell wall (Fig. 5B, arrow). Observation of a large number of sections showed that the extract from Microsphaeropsis sp. caused extensive damage to the host. Nearly all $R$. solani hyphae examined $(\approx 90 \%)$ exhibited obvious signs of disintegration. One of the most typical features of reaction was the retraction (Fig. 5B) and often the rupture of the plasma membrane (Fig. 5C). This degradation event was associated with a marked cytoplasmic disorganization ranging from an initial aggregation of the polyribosome matrix (Fig. 5B and C) to a gradual cytoplasm disintegration (Fig. 5D) leading to the occurrence of hyphal shells in which fibrillar and vesicular remnants (Fig. 5E) were the only visible features of previously living entities. Exposition of $R$. solani cells to the 1:4 dilution of Microsphaeropsis sp. extract induced some cytological disorders. However, their magnitude never reached those observed with the undiluted or 1:2 dilution of Microsphaeropsis sp. extract.

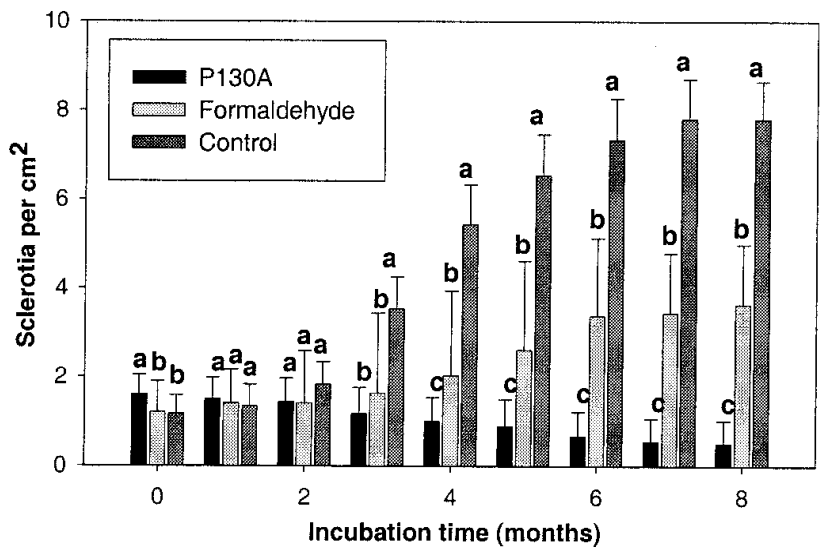

Fig. 1. Effect of dipping potato tuber in water, $2 \%$ formaldehyde, or a suspension of $10^{8}$ spores of Microsphaeropsis sp. on the production of Rhizoctonia solani sclerotia during storage at $4^{\circ} \mathrm{C}$. Values within a group of bars with the same letter are not significantly different according to the LSD test $(P<0.05)$. 


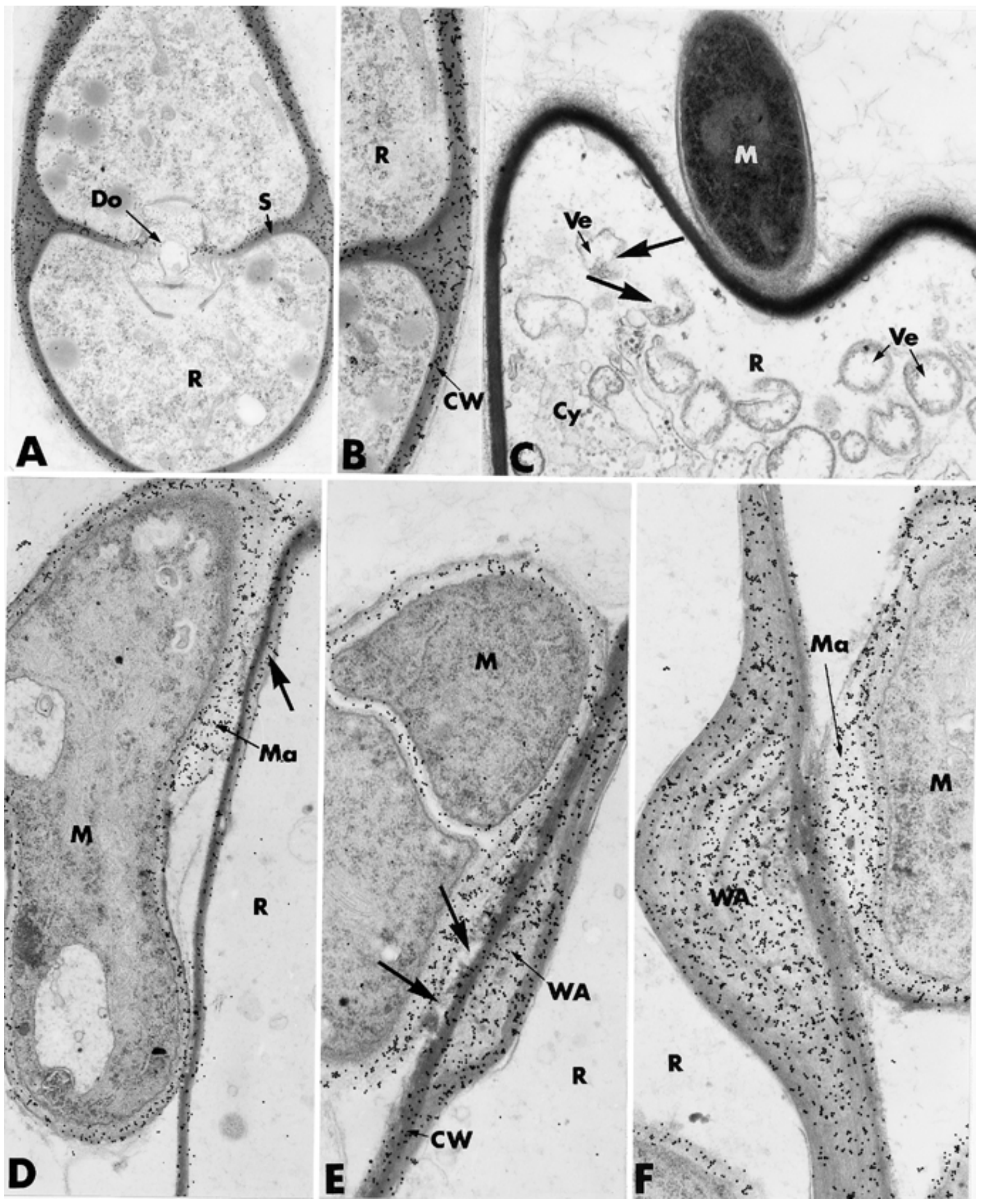

Fig. 2. A and B, Transmission electron micrographs of Rhizoctonia solani in pure culture and in D to F, dual culture with Microsphaeropsis sp. isolate P130A. Labeling of chitin with the wheat germ agglutinin (WGA)-ovomucoid-gold complex. A and B, A regular deposition of gold particles occurs over the wall (CW) of a $R$. solani $(\mathrm{R})$ hypha. Labeling is associated with the septum (S), whereas the dolipore (Do) and the cytoplasm are unlabeled $(\mathbf{A}, \times 16,000$ and $\mathbf{B}, \times 24,000)$. C, A Microsphaeropsis hypha (M) characterized by the strong electron density of its protoplasm establishes close contact with a cell of $R$. solani (R), causing some apparent mechanical pressure. The host cytoplasm (Cy) is markedly disorganized and vesicles (Ve) are frequently disrupted (arrows): $\times 24,000$. D and E, Contact between the pathogen (R) and the antagonist (M) mediated by an amorphous matrix (Ma) that is intensely labeled with the WGA-ovomucoid-gold complex. The pathogen cell wall is thickened at the site of potential antagonist penetration (arrow). Splitting of the thickened wall layers (CW) results in the formation of a wall apposition (WA). Some digested wall areas are visible (E, arrows) in the interfacial region $(\mathbf{D}, \times 24,000$ and $\mathbf{E}, \times 30,000)$. F, Formation of hemispherical, stratified wall apposition (WA) at the site of contact with the antagonist (M). Contact between both fungi is mediated by the chitin-enriched matrix $(\mathrm{Ma})(\times 30,000)$. 


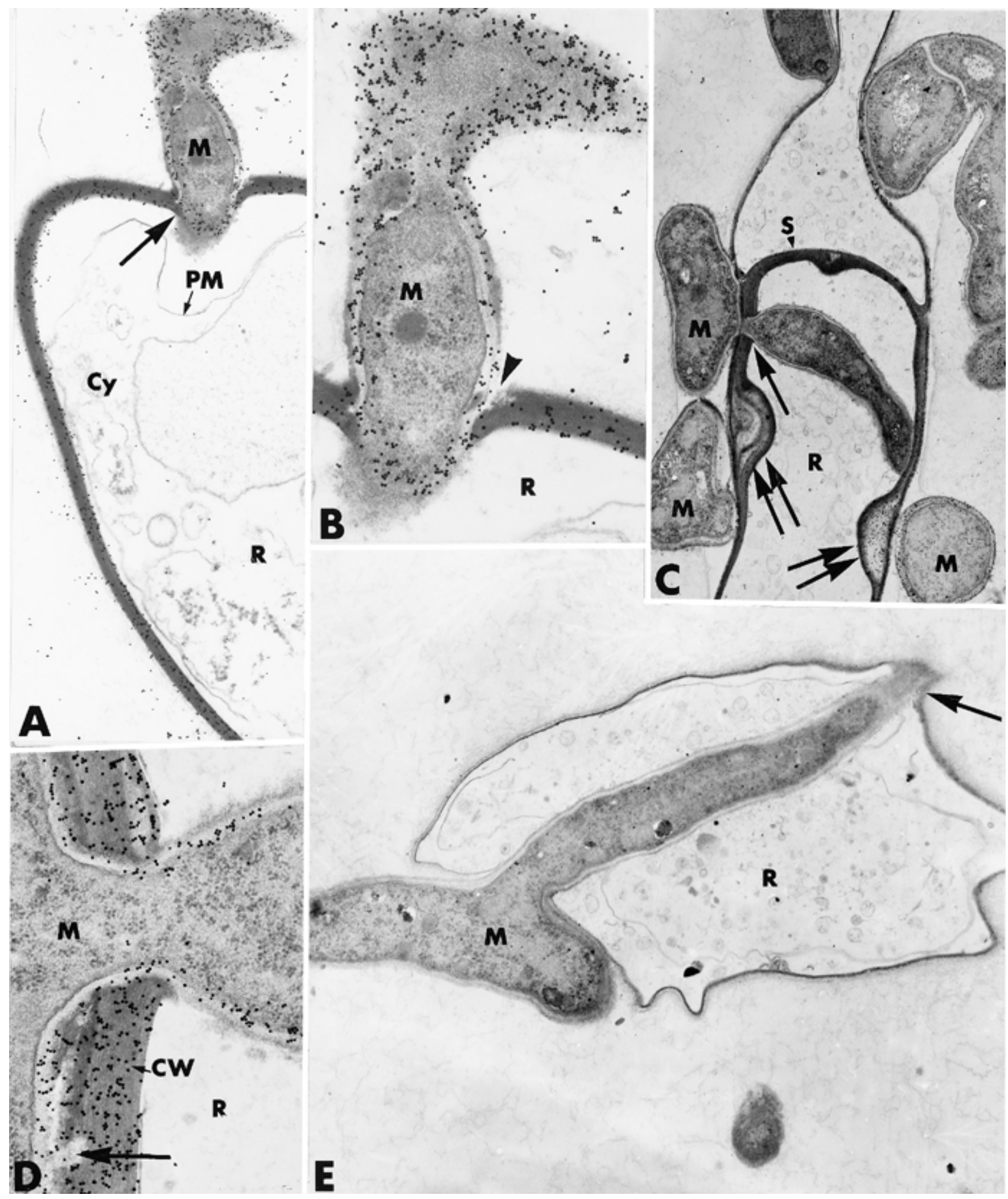

Fig. 3. Transmission electron micrographs of dual cultures between Microsphaeropsis sp. and Rhizoctonia solani. Labeling of chitin with the wheat germ agglutinin (WGA)-ovomucoid-gold complex. A and B, Penetration of the antagonist (M) occurs through a localized rupture of $R$. solani (R) cell wall (arrow). Plasma membrane (PM) is retracted, and cytoplasm (Cy) is highly disorganized. Penetration of the antagonist is associated with little host wall displacement (A, arrow) (A, $\times 20,000$ and $\mathbf{B}, \times 40,000)$. C, The antagonist (M) displays the ability to penetrate the thickened host cell wall (arrow). Wall appositions are seen at sites of contact with cells of the antagonist (double arrows) $(\times 8,000)$. D, Except for some well-delineated areas (arrow), the host cell wall (CW) is evenly labeled with the WGA-ovomucoid-gold complex on both sides of the channel of penetration $(\times 40,000)$. E, At an advanced stage of parasitism, antagonist (M) colonization of Rhizoctonia (R) hyphae coincides with dissolution of the host cytoplasm. A strong mechanical pressure is exerted in the area of potential release of the antagonist (arrow) $(\times 13,000)$. 


\section{DISCUSSION}

The percent germination of $R$. solani sclerotia produced in vitro and on potato tuber was significantly reduced when the sclerotia were incubated with mycelium or spores of Microsphaeropsis sp. As the period of contact between the antagonist and the sclerotia increased, the viability of sclerotia decreased to a minimum of approximately $5 \%$ after 35 days. These results are similar to those reported for Verticillium biguttatum $(25,38)$ and for Stachybotrys elegans (9) obtained at 14 to $20^{\circ} \mathrm{C}$. However, in our studies using tuber-borne sclerotia, the experiments were conducted at $4^{\circ} \mathrm{C}$, which is near the storage temperatures used for seed potato tubers. The number of sclerotia produced per square centimeter of tubers treated with water increased during the 8-month-storage period from 1.2 to 7.8, whereas on tubers treated with Microsphaeropsis $\mathrm{sp}$. it declined from 1.6 to 0.5 sclerotia per $\mathrm{cm}^{2}$. These results must be interpreted with care due to the difficulty in counting sclerotia on the tubers treated with the antagonist toward the end of the storage period, mainly because of the presence of pycnidia of Microsphaeropsis sp. produced on the sclerotia that could have masked sclerotia. Nevertheless, parasitized sclerotia did not germinate and, hence, will not contribute to the production of inoculum. These findings are in accordance with the results from other tests conducted with Microsphaeropsis sp. strain P130A at low temperature. Philion et al. (31) reported that on leaf disks kept at room temperature in complete darkness for 1 week, incubated at $4^{\circ} \mathrm{C}$ for 1 month, and at $10^{\circ} \mathrm{C}$ for an extra 3 months, Microsphaeropsis sp. strain P130A inhibited more than $98 \%$ of the asco-

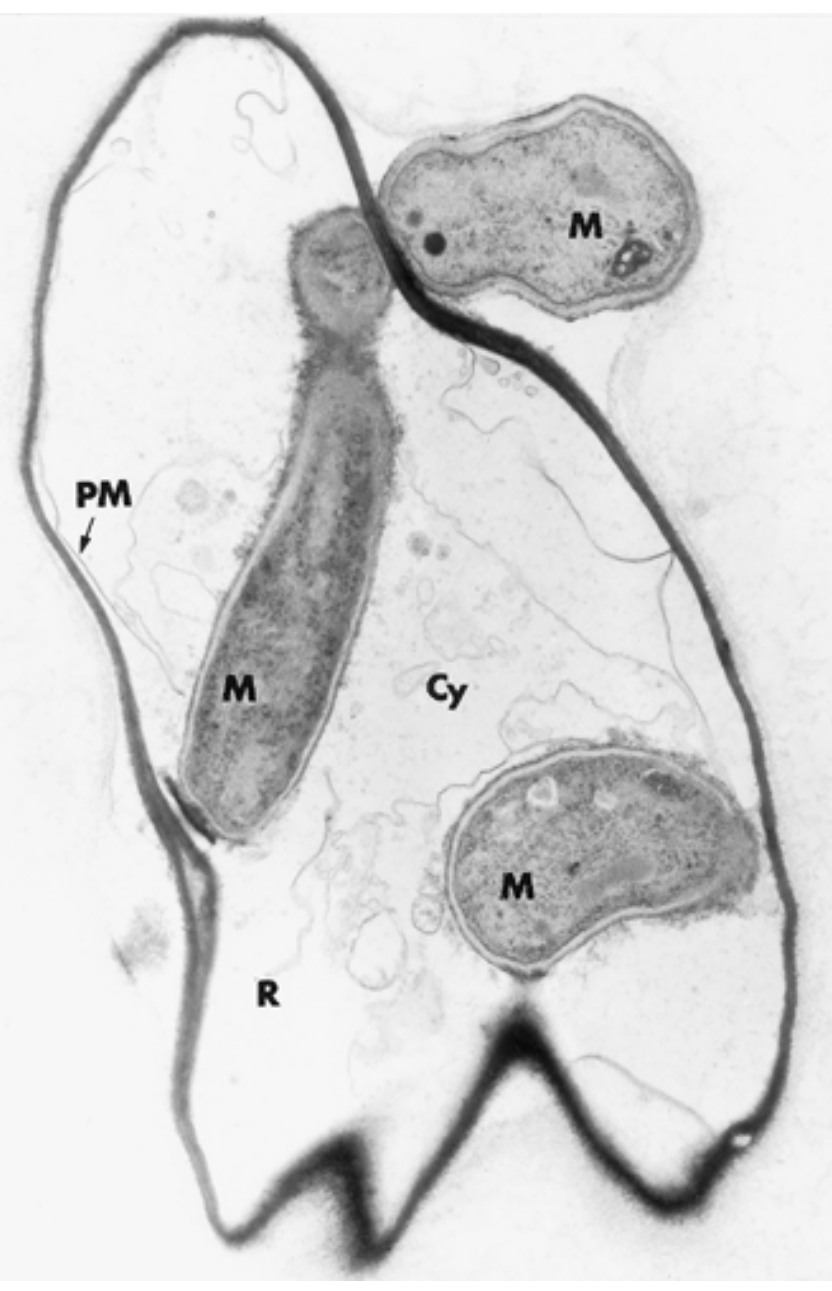

Fig. 4. Transmission electron micrographs of dual cultures between Microsphaeropsis sp. and Rhizoctonia solani. An invaded cell of $R$. solani (R) morphologically and structurally altered, evidenced by plasma membrane $(\mathrm{PM})$ disruption and cytoplasm $(\mathrm{Cy})$ alteration $(\times 15,000)$ spore production by Venturia inaequalis, the causal agent of apple scab. The capacity of Microsphaeropsis sp. to affect $R$. solani sclerotia production and viability at low temperature is a great advantage for tuber treatment during storage. In this experiment, the results obtained with Microsphaeropsis sp. were similar to those obtained with $2 \%$ formaldehyde, a positive control. However, formaldehyde is not well suited for use as a fungicide because it is a dangerous chemical to manipulate.

This investigation demonstrates that $R$. solani is highly vulnerable to an attack by the antagonistic fungus Microsphaeropsis sp. The present results are in line with earlier reports on the potential of this antagonist to cause adverse effects on Venturia inaequalis (8) and, to our knowledge, provide the first ultrastructural and cytochemical evidence that Microsphaeropsis sp. operates through a multifaceted process that requires the synergistic contribution of recognition events, antibiosis, and mycoparasitism.

TEM observations of the interaction region between both fungi provided evidence that the outcome of the interaction was likely determined by early recognitional events that triggered firm binding of the antagonist to the host cell surface, leading to a subsequent program of specific responses, such as adhesion and penetration of the antagonist in $R$. solani hyphae. Positive correlations between wall-bound components and recognition events in fungalfungal interactions have often been suggested $(4,14,16)$ and considered key determinants in the outcome of a given interaction. The observation that firm binding, often mediated by an amorphous matrix originating from Microsphaeropsis sp., preceded host cell penetration favors the assumption that specific molecular interactions occurred at the cell surface and determined a host recognition response. This, in turn, triggered a series of events, ultimately leading to penetration and invasion by the antagonist. The finding that a substantial amount of chitin occurred in this matrix suggests that receptors with $N$-acetylglucosamine-binding affinity are present at the cell surface of $R$. solani. Several lines of evidence have shown that lectin-sugar interactions likely correspond to early recognitional events that trigger a subsequent program of specific responses associated with the antagonistic process $(24,30)$. Although it is obvious that Microsphaeropsis sp. is an aggressive mycoparasite, our knowledge of the actual mechanisms operating in the initial events of the antagonistic process remains rudimentary and deserves further investigation.

One of the most striking features of the interaction between Microsphaeropsis sp. and $R$. solani was the abnormal formation of wall appositions at sites of potential antagonist entry. Such hemispherical deposits were subtended by deeply invaginated areas of the host plasma membrane and were heavily labeled by the WGAovomucoid-gold-complex. The mechanisms that control the process of wall-like formation at such sites is unclear, although it may be suggested that the accumulating material originates from the host cell wall through the swelling and stretching of preexisting polymers. Support to this concept comes from the observation that gradual splitting of $R$. solani cell walls coincides with chitin deposition. Interestingly, formation of such structural barriers at strategic sites may reflect a defense reaction elaborated by the pathogen in response to antagonist attack. Such a phenomenon, abundantly described in host-pathogen interactions $(6,7)$, has been seldom investigated in fungus-fungus interactions, although mention of similar fungal responses have been reported upon treatment with either chitosan (3) or fungicides (33). Because fungicides and chitosan are compounds known to interfere with positively charged molecules at the plasma membrane, it has been suggested that alteration in the lipid composition of the plasma membrane induced a deregulation of membrane-bound enzymes such as chitin synthases, leading to the deposition of chitin at unusual sites (3). In light of these earlier observations, one may speculate that toxic metabolites, produced by Microsphaeropsis sp., interfered with the plasma membrane of $R$. solani hyphae, causing a number of internal disturbances that resulted in the formation of wall appo- 

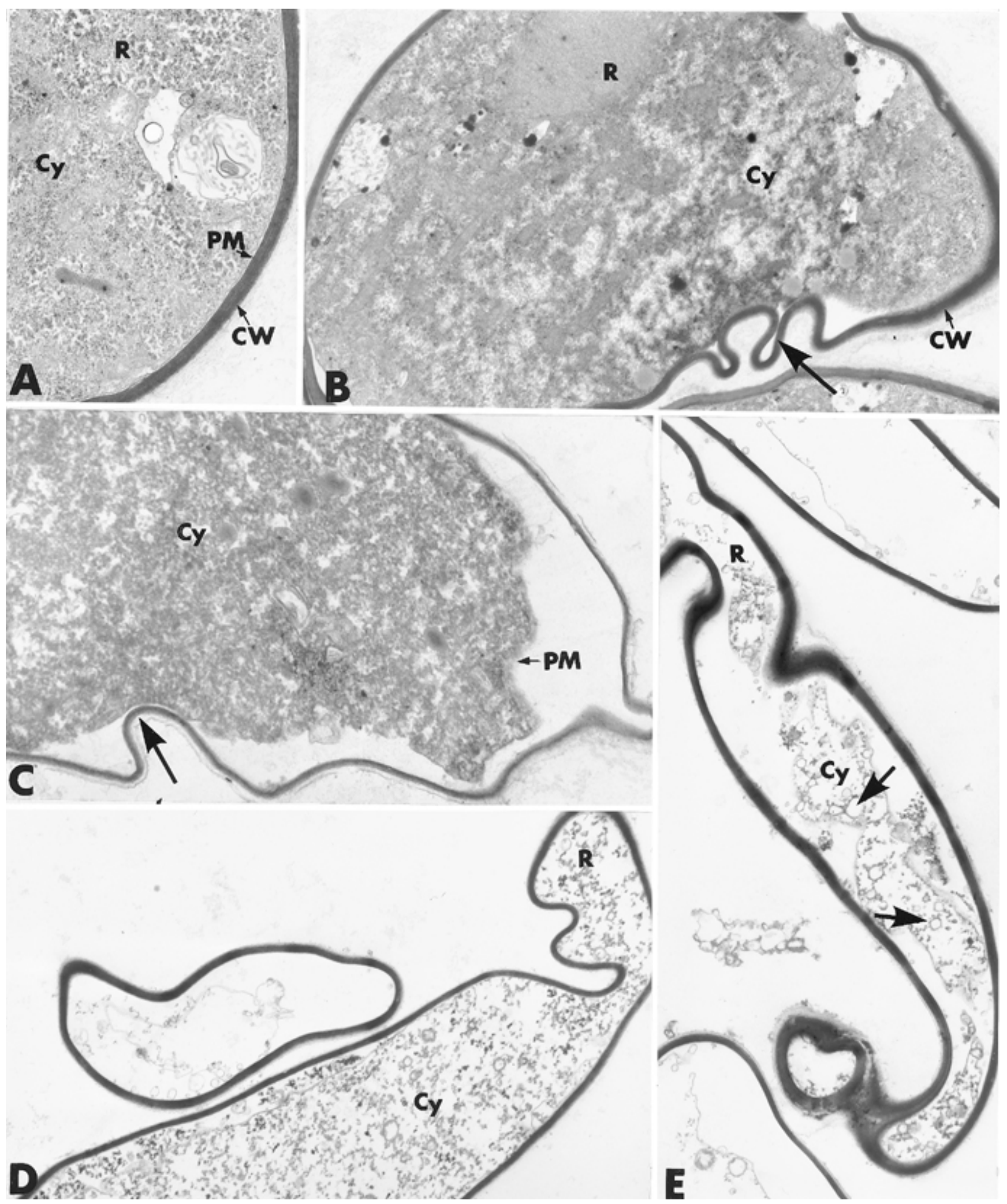

Fig. 5. Effect of active metabolites from Microsphaeropsis sp. on Rhizoctonia solani morphology and ultrastructure. A, Aspect of a Rhizoctonia cell exposed to chloroform alone. Cell integrity is preserved as shown by the plasma membrane (PM), which is appressed against the cell wall (CW) and by the granular cytoplasm $(\mathrm{Cy})(\times 20,000)$. B and C, Exposition to the crude extract at a 1:2 dilution from Microsphaeropsis cultures results in marked morphological alterations mainly characterized by a circonvolution of the cell wall (CW, arrows). One of the most typical features of reaction is the retraction of the plasma membrane (PM). The cytoplasm (Cy) is highly disorganized and organelles are no longer discernible $(\mathbf{B}, \times 13,000$ and $\mathbf{C}, \times 20,000)$. D and E, Exposition to the undiluted extract from Microsphaeropsis results in marked cell alterations leading to nearly complete cytoplasm (Cy) disintegration. Rhizoctonia cells are reduced to shells in which fibrillar and vesicular remnants (arrows) are the only visible features of previously alive entities $(\mathbf{D}, \times 8,000$ and $\mathbf{E}, \times 8,000)$. 
sitions. Support of the concept of toxin or antibiotic production by Microsphaeropsis sp. is corroborated by the finding that cells of $R$. solani underwent pronounced disorganization at a time when strict mycoparasitism did not yet occur. Similar features of reaction, observed in advance of host penetration, have often been reported and attributed to the rapid diffusion of toxic metabolites (1). The finding that crude extracts from Microsphaeropsis cultures were able to induce pronounced morphological and structural alterations of $R$. solani hyphae brings strong support to the concept that antibiosis is a key determinant of the antagonistic activity exerted by Microsphaeropsis sp.

Whatever the role played by the wall appositions, the antagonist displayed the ability to penetrate cells of $R$. solani, thus indicating the potential of Microsphaeropsis sp. to produce chitinolytic enzymes. This raises the question, to what extent does the weakening of the cell wall, through the action of Microsphaeropsis sp. chitinases, facilitate the diffusion of toxic compounds toward membrane receptors by increasing the wall permeability? Recent reports have focused on the synergistic action of hydrolytic enzymes (mainly chitinases) and antibiotics in the biocontrol process mediated by antagonistic microorganisms $(17,18,35)$, providing evidence that slight enzymatic alterations of the host cell walls were essential prerequisites for further antibiotic diffusion.

Based on current observations, the process by which Microsphaeropsis $\mathrm{sp}$. operates to control $R$. solani appears to involve a specific program of events including (i) attachment to the host through a chitin-enriched matrix; (ii) mechanical pressure and production of slight amounts of chitinases to weaken the host cell walls; (iii) secretion and diffusion of toxic metabolites with antifungal activity, causing severe disorders such as morphological changes, cytoplasm disorganization, and organelle alteration; (iv) further production of chitinases to allow host cell penetration and invasion; and (v) complete digestion of the host cells and release of the antagonist from moribund $R$. solani hyphae. These results provide evidence that Microsphaeropsis sp. has the potential to become an effective biocontrol agent against a wide range of pathogens. Preliminary experiments conducted on a number of plant-pathogenic fungi, including Pythium sp., Fusarium sp., and Phytophthora sp., tend to confirm the antifungal properties of this antagonist (O. Carisse, N. Benhamou, and M. Benyagoub, unpublished data). As the mechanisms underlying the biological functions of fungal antagonists are revealed, the possibility of controlling pathogen populations with selected microorganisms can be considered one of the most encouraging options for effective management of plant diseases in the near future.

\section{ACKNOWLEDGMENTS}

We thank M. Benyagoub for his help, A. Goulet, A. Ouimet, and I. Bujold for their excellent technical assistance, and M. Leggett from Philom Bios Inc., Saskatoon, Canada, for technical assistance and financial support.

\section{LITERATURE CITED}

1. Bélanger, R. R., Dufour, N., Caron, J., and Benhamou, N. 1995. Chronological events associated with the antagonistic properties of Trichoderma harzianum against Botrytis cinerea: Indirect evidence for sequential role of antibiosis and parasitism. Biocontrol Sci. Technol. 5:41-53.

2. Benhamou, N. 1989. Preparation and application of lectin-gold complexes. Pages 95-143 in: Colloidal Gold: Principles, Methods and Applications. M. Y. Hayat, ed. Academic Press, New York.

3. Benhamou, N. 1992. Ultrastructural and cytochemical aspects of chitosan on Fusarium oxysporum f. sp. radicis-lycopersici, agent of tomato crown and root rot. Phytopathology 82:1185-1193.

4. Benhamou, N., and Chet, I. 1993. Hyphal interactions between Trichoderma harzianum and Rhizoctonia solani: Ultrastructure and gold cytochemistry of the mycoparasitic process. Phytopathology 83:1062-1071.

5. Benhamou, N., and Chet, I. 1997. Cellular and molecular mechanisms involved in the interaction between Trichoderma harzianum and
Pythium ultimum. Appl. Environ. Microbiol. 63:2095-2099.

6. Benhamou, N., and Lafontaine, P. J. 1995. Ultrastructural and cytochemical characterization of elicitor-induced responses in tomato root tissues infected by Fusarium oxysporum f. sp. radicis-lycopersici. Planta 197:89-102.

7. Benhamou, N., Lafontaine, P. J., and Nicole, M. 1994. Induction to systemic resistance to Fusarium crown and root rot in tomato plants by seed treatment with chitosan. Phytopathology 84:1432-1444.

8. Benyagoub, M., Benhamou, N., and Carisse, O. 1998. Cytochemical investigation of the antagonistic interaction between a Microsphaeropsis sp. (isolate P130A) and Venturia inaequalis. Phytopathology 88:605-613.

9. Benyagoub, M., Jabaji-Hare, S. H., Banville, G., and Charest, P. M. 1994. Stachybotrys elegans: A destructive mycoparasite of Rhizoctonia solani. Mycol. Res. 98:493-505.

10. Bernier, J., Carisse, O., and Paulitz, T. C. 1996. Fungal communities isolated from dead apple leaves from orchards in Quebec. Phytoprotection 77:129-134.

11. Bujold, I. 2000. The use of a fungal antagonist to reduce the initial inoculum of Gibberella zeae on wheat and corn debris. M.S. thesis. McGill University, Ste Anne-de-Bellevue, Quebec.

12. Carisse, O., Philion, V., Rolland, D., and Bernier, J. 2000. Effect of fall application of fungal antagonists on spring ascospore production of the apple scab pathogen, Venturia inaequalis. Phytopathology 90:31-37.

13. Chand, T., and Logan, C. 1984. Post-harvest development of Rhizoctonia solani its penetration of potato tubers in North Ireland. Trans. Brit. Mycol. Soc. 82:615-619.

14. Chet, I. 1987. Trichoderma - Applications, mode of action and potential as a biocontrol agent of soilborne plant pathogenic fungi. Pages 137-160 in: Innovative Approaches to Plant Diseases. I. Chet, ed. John Wiley \& Sons, New York.

15. Chet, I., and Baker, R. 1981. Isolation and biocontrol potential of Trichoderma hamatum from soil naturally suppressive of Rhizoctonia solani. Phytopathology 71:286-290.

16. Chet, I., Harman, G. E., and Baker, R. 1981. Trichoderma hamatum: Its hyphal interaction with Rhizoctonia solani and Pythium spp. Microbiol. Ecol. 7:29-38.

17. Di Pietro, A., Lorito, M., Hayes, C. K., Broadway, R. M., and Harman, G. E. 1993. Endochitinases from Gliocladium virens: Isolation, characterization, and synergistic antifungal activity in combination with gliotoxin. Phytopathology 83:308-313.

18. Elad, Y., Chet, I., and Katan, J. 1980. Trichoderma harzianum: A biocontrol agent effective against Sclerotium rolfsii and Rhizoctonia solani. Phytopathology 70:119-121.

19. Frens, G. 1973. Controlled nucleation for the regulation of the particle size in monodisperse gold solutions. Nat. Phys. Sci. 241:20-22.

20. Harris, A. R., Schisler, D. A., Neate, S. M., and Ryder, M. H. 1993. Suppression of damping-off caused by Rhizoctonia solani, and growth promotion in bedding plants by binucleate Rhizoctonia sp. Soil Biol. Biochem. 26:263-268.

21. Howell, C. R. 1982. Effect of Gliocladium virens on Pythium ultimum, Rhizoctonia solani, and damping-off of cotton seedlings. Phytopathology 72:496-498.

22. Huppatz, J. L., Phillips, J. N., and Witrzens, B. 1983. Laboratory and glasshouse studies of the activity of carboxamide derivatives against Rhizoctonia solani in cotton. Plant Dis. 67:45-47.

23. Hwang, S. F., Swanson, T. A., and Evans, I. R. 1986. Characterization of Rhizoctonia solani isolates from canola in west central Alberta. Plant Dis. 70:681-683.

24. Inbar, J., and Chet, I. 1992. Biomimics of fungal cell-cell recognition by use of lectin-coated nylon fibers. J. Bacteriol. 174:1055-1059.

25. Jager, G., and Velvis, H. 1988. Inactivation of sclerotia of Rhizoctonia solani on potato tubers by Verticillium biguttatum, a soil-borne mycoparasite. Neth. J. Plant Pathol. 94:225-231.

26. Kataria, H. R., and Verma, P. R. 1982. Rhizoctonia solani damping-off and root rot of oilseed rape and canola. Crop Prot. 11:8-13.

27. Lewis, J. A., and Papavizas, G. C. 1987. Application of Trichoderma and Gliocladium in alginate pellets for control of Rhizoctonia solani damping-off. Plant Pathol. 36:438-446.

28. Morris, R. A. C., Coley-Smith, J. R., and Whipps, J. M. 1995. The ability of the mycoparasite Verticillium biguttatum to infect Rhizoctonia solani and other plant pathogenic fungi. Mycol. Res. 99:997-1003.

29. Nelson, E. B., and Maloney, A. P. 1992. Molecular approaches for understanding biological control mechanisms in bacteria: Studies of the interaction of Enterobacter cloacae with Pythium ultimum. Can. J. Plant Pathol. 14:106-114.

30. Nordbring-Hertz, B., and Chet, I. 1986. Fungal lectins and agglutinins. Pages 393-407 in: Microbial Lectins and Agglutinins: Properties and Biological Activity. D. Mirelman, ed. John Wiley \& Sons, New York.

31. Philion, V., Carisse, O., and Paulitz, T. C. 1997. In vitro evaluation of fungal isolates for their ability to influence leaf rheology, production of 
pseudothecia, and ascospores of Venturia inaequalis. Eur. J. Plant Pathol. 103:441-452.

32. Platt, H. W. 1989. Potato growth and tuber production as affected by inoculation of cut and whole seed with Rhizoctonia solani (AG-3) and the use of seed treatment fungicides. Am. Potato J. 66:365-378.

33. Robertson, R. W., and Fuller, M. S. 1990. Effects of the demethylase inhibitor, cyproconazole, on hyphal tip cells of Sclerotium rolfsii. II. An electron microscope study. Exp. Mycol. 14:124-135.

34. Rossall, S., and McKnight, S. E. 1991. Some effects of Bacillus subtilis (MBI 600) on the development of cotton and peanuts. Pages 88-92 in: Plant Growth-Promoting Rhizobacteria-Progress and Prospects. C. Keel, B. Koller, and G. Défago, eds. Int. Workshop Plant Growth-Promoting Rhizobacteria, 2nd. WPRS Bull. 14.

35. Shirmböck, M., Lorito, M., Wang, Y. L., Hayes, C. K., Arisan-Atac, I.,
Scala, F., Harman, G. E., and Kubicek, C. P. 1994. Parallel formation and synergism of hydrolytic enzymes and peptaibol antibiotics, molecular mechanisms involved in the antagonistic action of Trichoderma harzianum against phytopathogenic fungi. Appl. Environ. Microbiol. 60: 4364-4370.

36. Sippell, D. W., Davidson, J. G. N., and Sadasivaiah, R. S. 1985. Rhizoctonia solani root rot of rapeseed in the Peace River Region of Alberta. Can. J. Plant Pathol. 7:184-186.

37. Steel, R. G. D., and Torrie, J. H. 1980. Principles and Procedures of Statistics, a Biometrical Approach. 2nd ed. McGraw-Hill Book Co., New York.

38. Wicks, T. J., Morgan, B., and Hall, B. 1995. Chemical and biological control of Rhizoctonia solani on potato seed tubers. Aust. J. Exp. Agric. 35:661-664. 